\title{
Inventions New and Interesting
}

A Department Devoted to Pioneer Work in the Arts

\section{A Surgical Sewing Machine} By Robert H. Moulton

A ChICAGo surgeon, Dr. E. Wyllys Andrews, has $\mathrm{A}_{\text {invented an apparatus designed automatically to }}$ repair surgical incisions. Instead of being "sewed up" by hand on operating tables, future sufferers from appendicitis may fight out their troubles on a surgical sewing machine of the type about to be described.

For a number of years Dr. Andrews tried to perfect a sewing machine for wounds, constructed with platen, fixed needle and bobbin or shuttle. Yet in spite of the fact that several small hand and toy machines are made small enough to handle easily, none of them is capable of being brought into cavities or depths of wounds, or can be easily sterilized. Moreover, the machines in question place only what are called mattress stitches, no matter whether one or two threads.be used, and cann be easily adapted to overhand glover or interrupted stitching. After much study of the problem and discussion with the manufacturers of various machines, Dr. Andrews became satisfied that there could never be designed a shuttle machine that would be anything but clumsy, heavy and inefficient, and therefore dangerous about a wound.

It is different with forceps. With these, surgeons are familiar and know that they can place them in all sorts of deep and superficial locations even more readily than the hands or fingers, Dr. Andrews, therefore, set about to design forceps which would about to design forceps which would threads by merely opening and closing their blades, thereby combining some of the speed and accuracy of the sewing machine and the nicety and safeness of hand-sewing. The result of his experiments is a set of forceps which will actually sew the skin and deep layers more smoothly and rapidly than by hand. They are equally adapted for placing deep ligatures, single or multiple.

The object of these instruments is to gain speed, and, incidentally, regularity of spacing and of tension in the approximated edges. It must be admitted that this is as likely to be a drawback as an this is as likely to be a drawback as an
advantage. No machine can have the delicacy and tactile sense of the human fingers. But the question is, how much time can surgeons afford to sacrifice for careful suturing by the fingers?

A comparison of work in different clinics shows that some surgeons suture wounds rapidly. But the most of them require a large percentage of the total time of the entire operation for final closure, and nearly all take longer for this step than they themselves realize or would believe unless they have been timed by the watch.

A very few surgeons can perform certain ordinary operations, including the internal work and the closing of the wound, in five minutes, but the majority take from ten to fifteen minutes, while some very conscientious workers require from ten to twenty minutes for their careful wound closure alone. This is admirable from an anatomical standpoint, but it also involves the question of the injurious effect of prolonging anesthesia even in

simple cases. Yet the safety of the wound closure should never be sacrificed to speed. It is an inherent fault of hand suturing that it must be somewhat slow or else somewhat imperfect. Long practice with the needle gives speed, but only up to a certain point. To get beyond this point mechanical devices of some sort must be employed.

Dr. Andrews' device consists of a forceps with a needle carrying a thread, at the end of one blade. When the

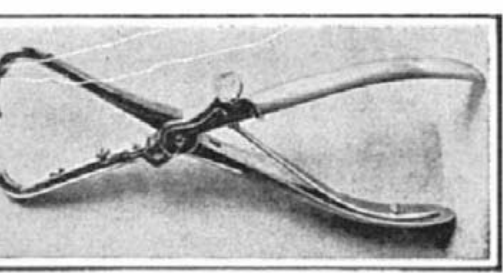

Before the stitch

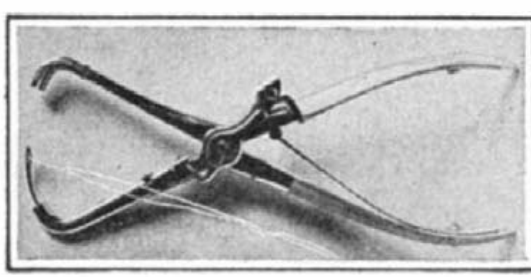

-and after

to be marked. When the saw is held in the position thown in the second picture, it can be used for marking t right angles to the edge of the board. This is very handy and a time saver, as it saves the time of reaching or a square every time a board is to be squared.

Putting Life into Street-Car Advertising Cards

MAGINE the Gold Dust Twins hard at work, one scrubbing the floor and the other scouring and polishing a pan; the Onyx hosiery girl raising a bit of her skirt and revealing her silk hosiery; the wearer of a Stetson hat tipping to every passer-by-visualize, if you can, all these things and many others like them in the space now occupied by the inanimate street-car advertising cards, and you at once begin to appreciate what animated advertising would mean if introduced commercially.

Bert Green, of New York city, is the handle of the forceps is closed the needle passes through the flesh and is seized automatically by the opposite blade, at the same time carrying the thread through the tissues. By pressing a thumb catch near the middle of the forceps the needle is released from the second blade and returns to its original position in the first blade, and thus is made ready for the next stitch, the operation requiring but a fraction of a second. The operation of the device is shown in the illustrations.

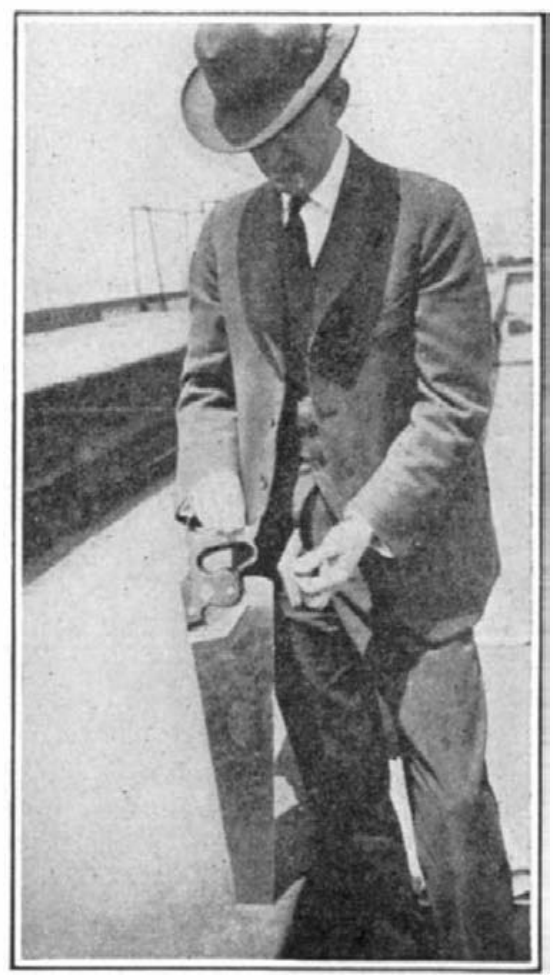

How the square and angle are attached to the saw blade

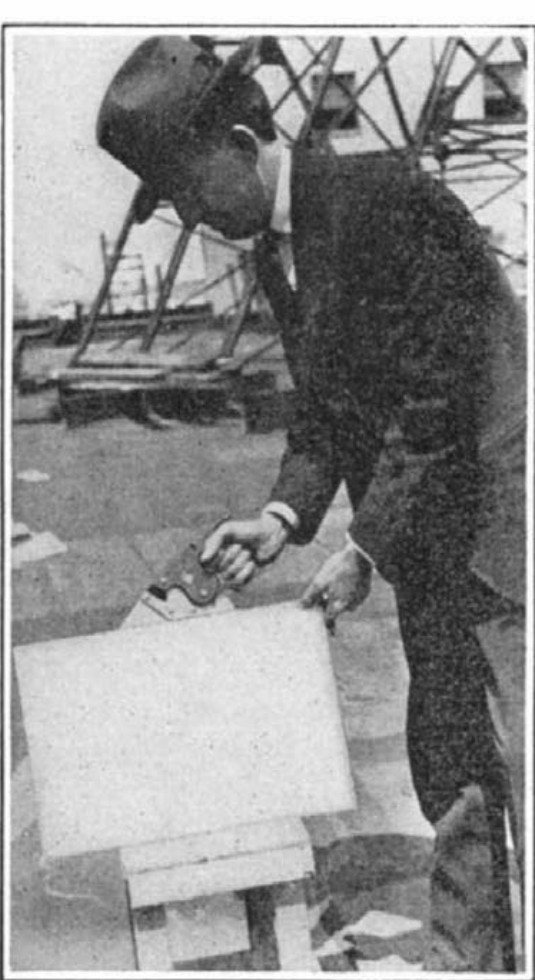

Laying of a 45 degree angle without reaching for a different tool nventor of the animated street-car advertisement; and incidentally, though appropriately, he is the manager of the animated cartoon department of a leading film producer Mr. Green has devised a number of movements which, when applied to street-car advertising signs, cause the figures in the advertisement to become animated. The movement is entirely due to the motion of the street-car in passing over the rail joints and in starting, reet-caping; there is absolutely no clock work nor any electricity required to operate the mechanism. Furthermore, the inventor has succeeded in reducing his mechanism to a point where the whole of the anim advertisement may be kept within one-half inch thickness, and it is so curved that it can be clipped in place in the usual way. There are two forms of movement which Mr. Green employs at the present time, although there is almost no end to the forms which may be developed and applied successfully. One of these movements is shown in the accompanying illustrations, and consists simply of a tube containing a metal ball. Obviously, when the car starts the ball is thrown backward, and when the car is brought to a stop the ball is thrown forward with reference to the direction in which the car is traveling. It will be noted that the ball, in moving back and forth, strikes end members which in turn are connected to and operate a pin member which slides in a slot, by means of a bowden wire transmission. The pin member in turn operates the animated figure of the advertisement-in this instance a man who continually tips his hat. An addition to this movement appears in the second illustration, in which it will be noted that an arrow member, coming through a slot so as to be seen on the face of the advertisement, is fitted over the ball and travels with it. This move-

Three Tools in One

THIS small device attached to a saw, enables the saw to be used as a square. It consists of two flanged plates, one fastened to each side of the saw near the handle with small bolts. When held in the position shown in our first cut, it makes a 45 -degree angle. This photograph shows the saw placed back of the board, showing how the plate engages the edge of the board ment is most effective, since the arrow travels back and forth over a certain line that is to be emphasized in the advertisement's appeal.

Aside from the ball movement, Mr. Green has successfully employed various arrangements of pendulums, which can be used for more rapid animation, such as the nodding of a head, the winking of eyes, arm movements, and so on. The cards present an interesting and practical innovation in advertising.

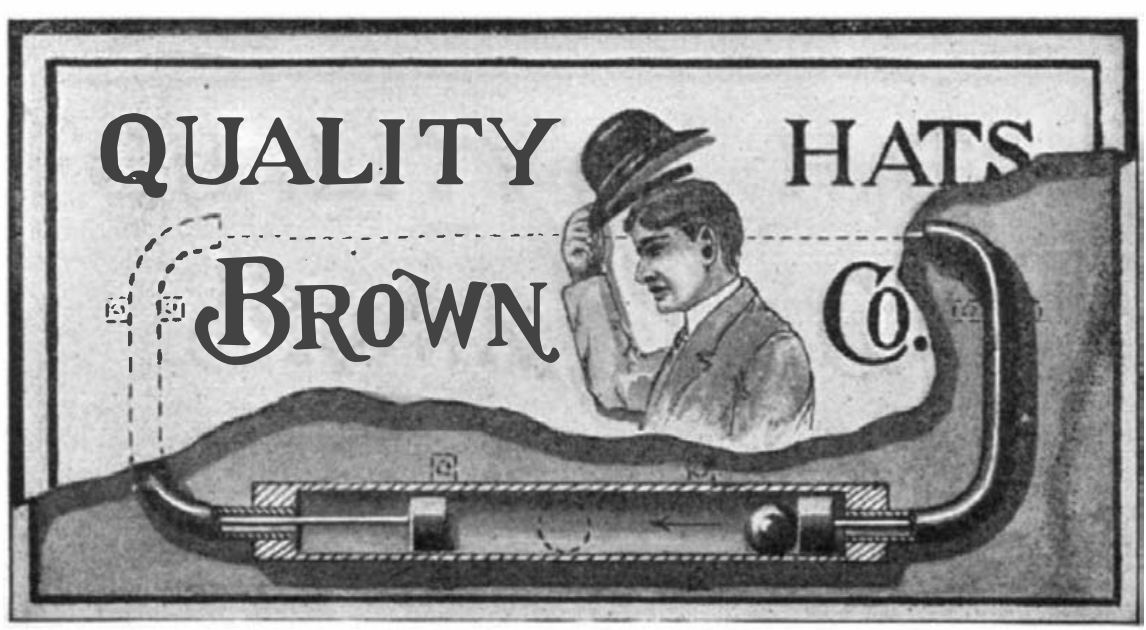

A typical animated advertising sign for street cars, partially cut away to disclose its mechanism

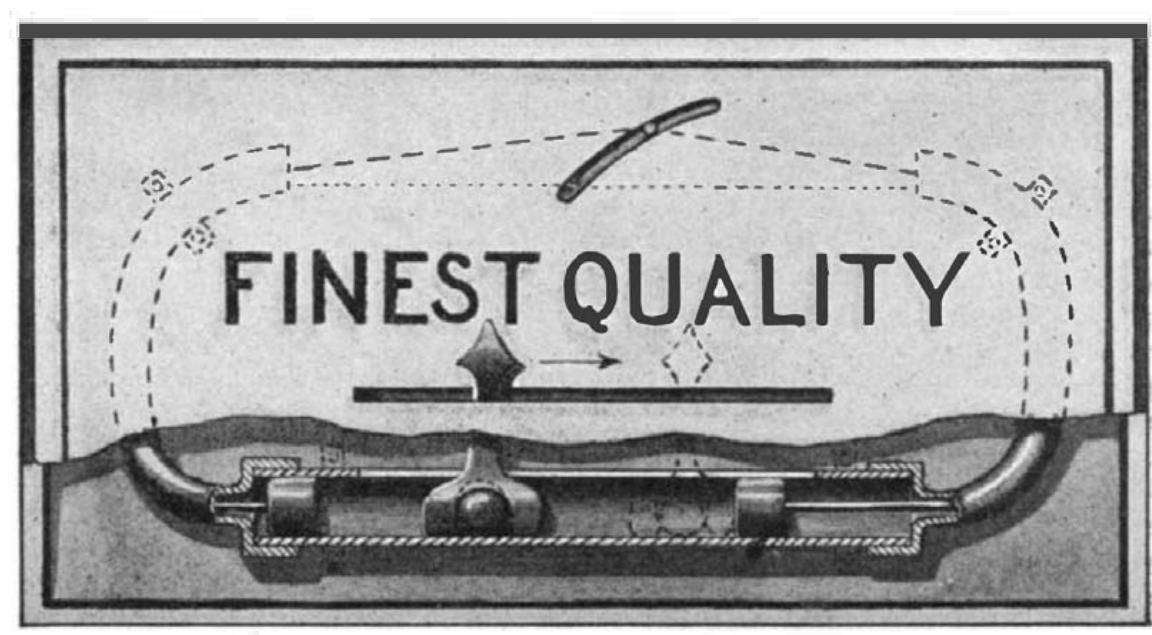

Another variation of the animated advertising sign, in which an arrow travels over a display line as a form of emphasis 